\title{
Role of Hepatocyte Nuclear Factor $4 \alpha$ in Regulating Hepatic Differentiation and the Inflammatory Response in HCC
}

\author{
Wen Li Zhou', Zhan Wang ${ }^{1}$, Ming Yong Miao², Yuan Sheng Zang ${ }^{1}$ \\ ${ }^{I}$ Department of Medical Oncology, Changzheng Hospital, Navy Medical University, Shanghai 200070, China; ${ }^{2}$ Department of \\ Biochemistry and Molecular Biology, Navy Medical University, Shanghai 200433, China
}

\begin{abstract}
Limited treatment options are available for hepatocellular carcinoma (HCC), especially in the advanced stage, which is associated with a poor prognosis. Many studies have demonstrated that hepatocyte nuclear factor $4 \alpha$ (HNF $4 \alpha$ ) plays an important role in hepatic differentiation and the carcinogenesis of HCC. HNF $4 \alpha$ critically regulates hepatic differentiation by controlling a large number of genes involved in hepatic functions including metabolism, xenobiotic detoxification, bile acid synthesis, and serum protein production. It has also been confirmed to play an important role in the inflammatory environment in HCC. Thus, HNF $4 \alpha$ is considered to be a promising target for the treatment of HCC. Some studies have demonstrated that regulating HNF $4 \alpha$ expression in HCC had beneficial effects in in vivo and in vitro experiments. We herein review the role of HNF $4 \alpha$ in regulating hepatic metabolism and the inflammatory response, aiming to provide some ideas on induced hepatic differentiation therapy and regulating the inflammatory microenvironment for the treatment of advanced HCC.
\end{abstract}

Key words: Hepatocyte nuclear factor $4 \alpha$ (HNF $4 \alpha$ ); Metabolism; Inflammation; Hepatic differentiation; Hepatocellular carcinoma (HCC)

\section{Introduction}

According to the cancer statistics released by the National Cancer Center in 2018, the annual incidence of primary hepatocellular carcinoma (HCC) in China was 466,000, accounting for about $55 \%$ of the global cases of the disease [1]. Surgical resection can be effective for the treatment of HCC, but most patients already have local dissemination or distant metastasis at the time of diagnosis, limiting the efficacy of surgery. Although there are several some other options for the treatment, they have limited benefit. For example, the overall survival (OS) in one study of patients treated with sorafenib for HCC compared with placebo was 10.7 vs 7.9 months [2]. In another phase 3 trial done at 152 sites in 21 countries, the median survival for patients treated with regorafenib following progression on sorafenib was increased by 2.8 months (10.6 vs 7.8 ) compared with the placebo control group [3]. The median OS of the commonly-used chemotherapy regimen, FOLFOX4, was only 6.4 months [4]. These studies demonstrate that the efficacy of targeted cancer therapies and chemotherapy for advanced HCC is relatively limited. In recent years, the research and application of immunological checkpoint therapy has been increasing exponentially, but more work is necessary to

Wen Li Zhou and Zhan Wang made an equal contribution to this paper. Corresponding authors: Wen Li Zhou, MD, PhD, Department of Medical Oncology, Changzheng Hospital, Navy Medical University, Shanghai 200070, China; Tel:+86 216654 0109; Email: doctorwinly@126. com; Yuan sheng Zang, MD, PhD, Department of Medical Oncology, Changzheng Hospital, Navy Medical University, Shanghai 200070, China; Tel:+86 216654 0109; Email: doctorzangys@163.com make these approaches more effective. These shed the light on hunting for alternative therapeutic strategies. Based on the biology of tumors, especially from the studies of pathways capable of controlling cell fate programs, induced differentiation strategies have been developed as a novel strategy.

Poor differentiation is an important hallmark of cancer cells. It has been increasingly recognized that liver cancer stem cells (LCSCs) are responsible for the carcinogenesis, recurrence and metastasis in HCC. The induced differentiation of LCSCs represents a new idea for the treatment of HCC. In addition, based on an analysis of whole-gene expression, it has been reported that the activation of embryonic stem cell (ESC)-like transcription is involved in hepatocellular carcinoma and strongly predicts early recurrence and metastasis [5-7]. These stem cells and stem celllike patterns of gene expression represent new target for HCC therapy. Many studies have suggested that hepatocyte nuclear factor $4 \alpha$ (HNF $4 \alpha$ ) is a promising target for inducing hepatic differentiation as a treatment for HCC. We herein review the roles of HNF $4 \alpha$ in regulating hepatic metabolism and the inflammatory response, aiming to provide some ideas on induced hepatic differentiation therapy.

\section{Structural Domains of HNF $4 \alpha$ and Its Iso- forms}

HNF4 is a nuclear hormone receptor protein mostly expressed in the liver but also expressed at lower levels in the gut, kidney, and pancreatic beta cells. Three different isoforms have been identified, HNF $4 \alpha$, HNF $4 \beta$ and HNF $4 \gamma$. The structure of HNF $4 \alpha$ protein has two transactivation 
functional domains, activation function 1 and 2 (AF-1 and AF-2), located at the $\mathrm{N}$ - and C-terminus respectively. A ligand-binding domain (LBD) is located adjacent to AF-2 and transactivates genes in a ligand-dependent manner. HNF $4 \alpha$ also contains a repressor domain (region $\mathrm{F}$ ) inhibiting the access of coactivators to AF-2, which has not been characterized in other HNF families. The gene of HNF- $4 \alpha$ has two promoters $\mathrm{P} 1$ and $\mathrm{P} 2$, and each produce different versions of HNF $4 \alpha$ protein (Figure 1). Hepatocytes express P1-only isoforms, while intestinal epithelial cells express both $\mathrm{P} 1$ and $\mathrm{P} 2$ isoforms. In contrast to $\mathrm{P} 1-\mathrm{HNF} 4 \alpha, \mathrm{P} 2-\mathrm{HNF} 4 \alpha$ is markedly upregulated and serves as an oncogene-associated protein in HCC [8]. A recent study shows that the expression of $\mathrm{P} 1$ isoforms rapidly decreases, whereas $\mathrm{P} 2$ isoform expression increases in the early stages of colon tumorigenesis [9]. Thus, the different isoforms of HNF $4 \alpha$ play different roles in the carcinogenesis.

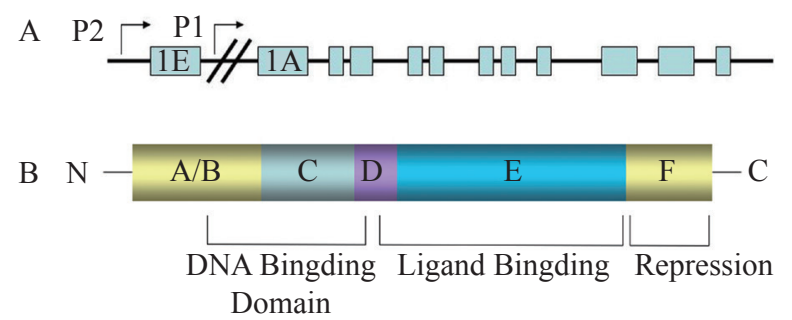

Figure 1 The hepatocyte nuclear factor $4 \alpha$ gene and its functional domains. It has two transactivation functional domains, the DNA binding domain and the ligand-binding domain. $\mathrm{HNF} 4 \alpha$ also contains a repressor domain (region F) that has an inhibitory function. Transcription through the P1 promoter allows the inclusion of exon $1 \mathrm{~A}$, which encodes the $\mathrm{N}$-terminal domain of HNF $4 \alpha$, whereas the P2 promoter results in the inclusion of exon $1 \mathrm{E}$, but the exclusion of exon $1 \mathrm{~A}$

\section{HNF 4 $\alpha$ Regulates Hepatic Differentiation}

Fetal liver development has implications for hepatic differentiation and maturation, and is associated with a series of reciprocal tissue interactions [10]. HNF $4 \alpha$-null mice died during embryogenesis, and HNF $4 \alpha$ is required for the formation of an active hepatic parenchyma [10]. Moreover, recent in vitro experiments using tetraploid aggregation suggested that HNF $4 \alpha$ is indispensable for hepatocyte differentiation [11]. The directed differentiation of hepatocytes from pluripotent stem cells (PSCs), including embryonic and induced pluripotent stem cells, has demonstrated that HNF $4 \alpha$ is highly expressed in both differentiated and mature hepatocytes $[12,13]$. During the process of induced hepatic differentiation, there is enhanced hepatic function, especially metabolic activity. As a key member of the HNF4 family, HNF $4 \alpha$ was shown to critically regulate a large number of genes involved in most hepatocyte functions, including energy metabolism, xenobiotic detoxification, bile acid synthesis, and serum protein production [14]. We previously reported that the levels of albumin, CYP3A4, TTR, AFP, fibronectin and transthyretin were all regulated by HNF $4 \alpha$ [12]. Liver X receptor $\alpha(\mathrm{LXR} \alpha / \mathrm{NR} 1 \mathrm{H} 3)$ accelerates hepatic differentiation in an HNF $4 \alpha$-dependent manner, with hepatocyte-like cells exhibiting some functions of mature hepatocytes, including cytochrome P450 enzyme activity, secretion of urea and albumin, and an increase in glycogen storage [15].

A recent study demonstrated that deletion of hepatic HNF $4 \alpha$ can inhibit hepatic gluconeogenesis, hepatic lipid export, and intestinal lipid absorption, thus increasing the dependence on dietary carbohydrates and endogenous lipids for energy [16]. By ectopically expressing a distinct combination of transcription factors (Foxa2, HNF $4 \alpha$ and C/ebp $\alpha$ ), Iacob $\mathrm{R}$ et al. induced a mature hepatocyte phenotype in an adult liver-derived progenitor cell population, and found that albumin secretion increased incrementally in single (Foxa2), double (Foxa2, HNF $4 \alpha$ ) and triple-transduced cells (Foxa2, HNF 4 $\alpha, \mathrm{C} / \mathrm{ebp} \alpha$ ) and reached levels observed in primary hepatocytes. Glycogen storage and ureagenesis were also induced in the triple-transduced cells, but at lower levels compared to primary hepatocytes [17]. Another study showed that HNF $4 \alpha$ can co-recruit HDAC3-PROX1, regulating the expression of a gene program controlling lipid homeostasis [18]. It has been demonstrated that excess iron promotes the formation of reactive oxygen species, resulting in cellular toxicity. Liver-specific HNF $4 \alpha$-null mice exhibit hypoferremia and a significant change in hepatic gene expression, demonstrating that HNF $4 \alpha$ also plays an important role in iron homeostasis [19].

The liver is the main organ involved in drug and xenobiotic metabolism, including inactivation or bioactivation. This metabolism consists of three phases: Phase I is carried out by hundreds of cytochrome P450 enzymes (CYPs). Phase II helps to eliminate Phase I products, and is carried out by glutathione S-transferases, sulfur transferase, UDP-glucuronosyltransferase, etc. Phase III transporters include P-glycoprotein, multidrug resistance-associated protein and others. The gene expression of many of these enzymes is regulated by HNF $4 \alpha$ [13]. Jeong $H$ and his colleagues reported that promoter transactivation of the cytochrome P450s (CYP) such as CYP2D6, CYP2C9 and CYP2E1 by HNF $4 \alpha$ is enhanced during pregnancy [20, 21]. Recombinant HepG2 cells modified by the combination of HNF4 $\alpha$ and other transcription factors exhibited enhanced ammonia metabolism and CYP enzyme activity compared with control cells [22]. Nishikawa T et al. found that HNF $4 \alpha$ - targeted therapy can reverse deteriorating hepatic functions, such as worsening encephalopathy and increased ammonia levels in rats, demonstrating that HNF $4 \alpha$ has a role in hepatocyte ammonia metabolism [23]. Based on these studies, we can see the important role of HNF $4 \alpha$ in maintenance and enhancement of hepatic function, especially hepatic metabolism. 


\section{HNF $4 \alpha$ Regulates the Inflammatory Environ- ment in HCC}

Research has demonstrated that HNF $4 \alpha$ is involved in inflammation processes occurring in the liver and gastrointestinal tract. The liver responds to stimuli by producing a large number of acute-phase reactants (APRs) including TNF- $\alpha$, TGF- $\beta$, IL- 1 and IL- 6 . HNF $4 \alpha$ has been confirmed to play a critical role in inflammation through the regulation of APR gene transcription.

One study showed that HNF $4 \alpha$ suppresses IL6-STAT3 activation and liver inflammation to regulate hepatocarcinogenesis. It was the first study to report that the HNF $4 \alpha$-STAT3 axis links inflammation and HCC [24]. They also found that the loss of HNF $4 \alpha$ results in IL-6 receptor-STAT3 activation via the inhibition of MicroRNA (miR)-124, while STAT3 upregulates the expression of miR-629 and miR-24 and suppresses the expression of HNF $4 \alpha$ [24]. Ning BF et al. reported that HNF $4 \alpha$ reduction is an independent risk factor for the patient prognosis, where patients with high HNF $4 \alpha$ expression and low expression of RelA (one subunit of NF- $\kappa \mathrm{B}$ ) had superior overall survival and longer disease-free survival. In addition, using the combination of HNF $4 \alpha$ and RelA exhibited improved prognostic accuracy in HCC patients, providing novel prognostic biomarkers and therapeutic targets from the viewpoint of the inflammatory environment in HCC. They also found that HNF $4 \alpha$ can upregulate miR-7 and miR-124, while NF- $\kappa \mathrm{B}$-mediated upregulation of miR-21 resulted in decreased HNF $4 \alpha$ levels [25], suggesting a possible HNF $4 \alpha-\mathrm{NF}-\kappa \mathrm{B}$ feedback circuit in HCC.

The activity of HNF $4 \alpha$ can be regulated by some cytokines at the level of its interactions with cofactors to promote transcriptional activity. It was reported that IL-1 $\beta$, TNF- $\alpha$ and IL- 6 cause a dynamic change in the phosphorylation of HNF4 or in its transcription [26,27]. In HNF $4 \alpha$ knock-down HepG2 cell lines, Wang Z et al. found that the majority $(519 / 597,87 \%)$ of probe-sets regulated by cytokines were also regulated by HNF $4 \alpha$. That study showed that HNF $4 \alpha$ plays a significant role in regulating the inflammatory response via hepatic gene expression [28]. From these studies, it can be concluded that HNF $4 \alpha$ has a major role in the inflammatory microenvironment, suggesting a new way to regulate or eradicate inflammation-related cancer.

\section{HNF $4 \alpha$ as a Potential Therapeutic Target for HCC}

Many studies have demonstrated that HNF $4 \alpha$ plays an important role in the carcinogenesis of HCC. It has been clearly demonstrated in both rodents and humans that the progression of HCC is associated with downregulation of HNF $4 \alpha$. Lazarevich NL et al. identified dysregulation of HNF $4 \alpha$ as a marker for epithelial tumor progression [29]. Enane FO et al. reported that transcription factors (including HNF $4 \alpha$, Hlf, and Nr1h4) were drivers of terminal epithelial differentiation, and they identified hundreds of hepatocyte epithelial-differentiation genes with significantly decreased expression in HCC [30]. Walesky $\mathrm{C}$ et al. found that deletion of HNF $4 \alpha$ in adult hepatocytes results in increased hepatocyte proliferation and promotion of diethylnitrosamine (DEN)-induced hepatic tumors secondary to aberrant c-Myc activation [31]. Ning BF et al. reported that overexpression of HNF $4 \alpha$ suppresses DEN-induced HCC in rats, suggesting that HNF $4 \alpha$ may have the ability to inhibit hepatocyte proliferation [32]. Together, these studies imply that HNF $4 \alpha$ is a promising marker and therapeutic target for HCC. More research is needed on the regulation of HNF $4 \alpha$ expression and transcriptional activity in order to fully elucidate its roles in normal and malignant hepatocytes.

As a group of small non-coding RNA molecules, microRNAs play a role in the transcriptional and post-transcriptional regulation of a variety of genes. A large number of miRNAs have been shown to regulate hepatocarcinogenesis by affecting the expression of HNF $4 \alpha$, thus contributing to liver cell differentiation, growth, survival and apoptosis. Ning BF et al. reported that HNF $4 \alpha$ can upregulate miR-7 and miR-124, and also found that NF- $\kappa$ B upregulated miR-21 in hepatoma cells, which decreased the HNF $4 \alpha$ levels [25]. Zhang Y and colleagues found that miR-34 $\alpha$ is essential for HNF $4 \alpha$ expression and regulates triglyceride accumulation in human and murine hepatocytes. miR-34 $\alpha$ inhibits very low-density lipoprotein secretion and promotes liver steatosis and hypolipidemia in an HNF $4 \alpha$-dependent manner [33].

Several post-translational modifications of HNF $4 \alpha$ have been documented. For example, the function and stability of HNF $4 \alpha$ are regulated by phosphorylation, acetylation and ubiquitination. Modification by the small ubiquitin-related modifier (SUMO), SUMOylation, is a post-translational modification that affects many proteins related to cellular processes such as differentiation, cell cycle progression, gene transcription, and protein localization. Our previous study showed that HNF $4 \alpha$ is regulated by SUMOylation, which seems to result in RNF4-mediated ubiquitination, followed by its degradation [12]. During the hepatocyte differentiation of HepaRG progenitors, the expression of HNF $4 \alpha$ was increased by progressive demethylation, increasing the metabolic activity of hepatocytes, as evidenced by increased albumin, aldolase B, glutathione S-transferase $\alpha$ and $\mathrm{Cy}$ p3A4 [34]. Some kinases (PKA, PKC, AMPK) have been shown to phosphorylate and decrease the activity of HNF $4 \alpha$. Activation of the ERK1/2 signaling pathway inhibits the expression of HNF $4 \alpha$ to regulate HNF $4 \alpha$-dependent hepatic gene expression [35].

Moreover, HNF $4 \alpha$ can regulate hepatic differentiation by interacting with other transcription factors. Jing $\mathrm{R}$ et al. found that HSP90 $\beta$ directly interacts with HNF $4 \alpha$ protein to regulate its half-life. They demonstrated that HSP90 promotes the conversion of iPSC-derived endoderm to a hepatic fate and regulates HNF $4 \alpha$ turnover [36]. HNF $4 \alpha$ also 
interacts with some nuclear receptors, such as the retinoid X receptor, peroxisome proliferator-activated receptor (PPAR), farnesoid X receptor, glucocorticoid receptor, vitamin D receptor, and androstane receptor [37-39]. Kodama $\mathrm{S}$ et al. discovered that the pregnane $\mathrm{X}$ receptor (PXR) can suppress the expression of HNF $4 \alpha$, resulting in upregulation of insulin-like growth factor-binding protein (IGFBP), which is of note because the PXR-HNF $4 \alpha$-IGFBP signaling pathway plays an important role in tumor invasiveness [40].

Of interest, studies have shown that retinoic acid, ginsenoside Rg3 and 18ß-glycyrrhetinic acid can induce hepatic differentiation at least partly via modulation of HNF $4 \alpha$ [41-43]. These findings suggest that it should be possible to induce differentiation in HCC. However, further studies are needed to fully elucidate the mechanism(s) by which this can occur and to determine ways to utilize these findings therapeutically.

\section{Conclusion}

As discussed above, the expression of HNF $4 \alpha$ is suppressed in HCC, and it has been demonstrated that its downregulation plays a critical role in oncogenesis and the progression of HCC. Many researchers have demonstrated that HNF $4 \alpha$ is critical for hepatic differentiation via both driving the formation of hepatocytes and maintaining a mature phenotype. HNF $4 \alpha$ critically regulates hepatic differentiation by controlling a large number of genes involved in hepatic functions including energy metabolism, xenobiotic detoxification, bile acid synthesis, and serum protein production. Besides its role in hepatic differentiation, studies have also identified an important role for HNF $4 \alpha$ in the inflammatory environment in HCC. Enhancing HNF $4 \alpha$ expression or activity presents a possible strategy for the treatment of HCC. Because HNF $4 \alpha$ can be regulated by post-translational modifications, interactions with microRNAs, and so on, there are a number of potential targets for this strategy. However, in contrast to acute promyelocytic leukemia, the development of differentiation therapy for solid tumors is far from satisfactory. The discovery of new drugs with favorable tumor penetration rates, high affinity and specificity for molecular recognition and targeting is needed prior to the use of induced hepatic differentiation therapy for HCC. Novel drug delivery systems, such as liposomes, nanoparticles and niosomes, might be used to improve the intracellular delivery, with better penetration and targeting specificity, helping to overcome some of the issues associated with differentiation therapy. Moreover, further studies are needed to investigate the possible strategies of regulating inflammatory microenvironment by HNF $4 \alpha$ in HCC.

\section{Acknowledgements}

Dr. Wenli Zhou was supported by the National Natural Science Foundation of China (No. 81300345).

\section{Conflict of Interests}

The authors declare that there are no conflicts of interest.

\section{References}

1. Chen W, Sun K, Zheng R, Zeng H, Zhang S, Xia C, Yang Z, Li H, Zou X, He J. Cancer incidence and mortality in China, 2014. Chin J Cancer Res 2018;30(1):1-12.

2. Llovet JM, Ricci S, Mazzaferro V, Hilgard P, Gane E, Blanc JF, de Oliveira AC, Santoro A, Raoul JL, Forner A, Schwartz M, Porta C, Zeuzem S, Bolondi L, Greten TF, Galle PR, Seitz JF, Borbath I, Haussinger D, Giannaris T, Shan M, Moscovici M, Voliotis D, Bruix J. Sorafenib in advanced hepatocellular carcinoma. N Engl J Med 2008;359(4):37890

3. Finn RS, Merle P, Granito A, Huang YH, Bodoky G, Pracht M, Yokosuka O, Rosmorduc O, Gerolami R, Caparello C, Cabrera R, Chang C, Sun W, LeBerre MA, Baumhauer A, Meinhardt G, Bruix J. Outcomes of sequential treatment with sorafenib followed by regorafenib for HCC: Additional analyses from the phase III RESORCE trial. J Hepatol 2018;69(2):353-8.

4. Qin S, Bai Y, Lim HY, Thongprasert S, Chao Y, Fan J, Yang TS, Bhudhisawasdi V, Kang WK, Zhou Y, Lee JH, Sun Y. Randomized, multicenter, open-label study of oxaliplatin plus fluorouracil/leucovorin versus doxorubicin as palliative chemotherapy in patients with advanced hepatocellular carcinoma from Asia. J Clin Oncol 2013;31(28):3501-8.

5. Wang L, Li Y, Xu J, Zhang A, Wang X, Tang R, Zhang X, Yin H, Liu M, Wang DD, Lin PP, Shen L, Dong J. Quantified postsurgical small cell size CTCs and EpCAM(+) circulating tumor stem cells with cytogenetic abnormalities in hepatocellular carcinoma patients determine cancer relapse. Cancer Lett 2018;412:99-107.

6. Yin X, Zheng SS, Zhang L, Xie XY, Wang Y, Zhang BH, Wu W, Qiu $\mathrm{S}$, Ren ZG. Identification of long noncoding RNA expression profile in oxaliplatin-resistant hepatocellular carcinoma cells. Gene 2017;596:5388.

7. Ramesh V, Ganesan K. Integrative functional genomic delineation of the cascades of transcriptional changes involved in hepatocellular carcinoma progression. Int J Cancer 139(7):1586-97.

8. Cai SH, Lu SX, Liu LL, Zhang CZ, Yun JP. Increased expression of hepatocyte nuclear factor 4 alpha transcribed by promoter 2 indicates a poor prognosis in hepatocellular carcinoma. Therap Adv Gastroenterol 2017;10(10):761-71.

9. Babeu J-P, Jones C, Geha S, Carrier JC, Boudreau F. P1 promoter-driven HNF $4 \alpha$ isoforms are specifically repressed by $\beta$-catenin signaling in colorectal cancer cells. J Cell Sci 2018;131(13):jcs214734.

10. Ang LT, Tan AKY, Autio MI, Goh SH, Choo SH, Lee KL, Tan J, Pan B, Lee JJH, Lum JJ, Lim CYY, Yeo IKX, Wong CJY, Liu M, Oh JLL, Chia CPL, Loh CH, Chen A, Chen Q, Weissman IL, Loh KM, Lim B. A Roadmap for human liver differentiation from pluripotent stem cells. Cell Rep 2018;22(8):2190-205.

11. Hayhurst GP, Lee YH, Lambert G, Ward JM, Gonzalez FJ. Hepatocyte nuclear factor 4alpha (nuclear receptor 2A1) is essential for maintenance of hepatic gene expression and lipid homeostasis. Mol Cell Biol 2001;21(4):1393-403.

12. Zhou W, Hannoun Z, Jaffray E, Medine CN, Black JR, Greenhough S, Zhu L, Ross JA, Forbes S, Wilmut I, Iredale JP, Hay RT, Hay DC. 
SUMOylation of HNF $4 \alpha$ regulates protein stability and hepatocyte function. J Cell Sci 2012;125(15):3630-5.

13. Szkolnicka D, Farnworth SL, Lucendo-Villarin B, Storck C, Zhou W, Iredale JP, Flint O, Hay DC. Accurate prediction of drug-induced liver injury using stem cell-derived populations. Stem Cells Transl Med 2014;3(2):141-8.

14. Martinez-Jimenez CP, Kyrmizi I, Cardot P, Gonzalez FJ, Talianidis I. Hepatocyte nuclear factor $4 \alpha$ coordinates a transcription factor network regulating hepatic fatty acid metabolism. Mol Cell Biol 2010;30(3):565-77.

15. Chen KT, Pernelle K, Tsai YH, Wu YH, Hsieh JY, Liao KH, Guguen-Guillouzo C, Wang HW. Liver X receptor alpha (LXRalpha/ $\mathrm{NR} 1 \mathrm{H} 3$ ) regulates differentiation of hepatocyte-like cells via reciprocal regulation of HNF4alpha. J Hepatol 2014; 61(6):1276-86.

16. Huck I, Morris EM, Thyfault JP, Apte U. Hepatocyte-specific hepatocyte nuclear factor 4 alpha (HNF $4 \alpha$ ) deletion decreases resting energy expenditure by disrupting lipid and carbohydrate homeostasis. bioRxiv 2018:401802.

17. Iacob R, Rüdrich U, Rothe M, Kirsch S, Maasoumy B, Narain N, Verfaillie CM, Sancho-Bru P, Iken M, Popescu I, Schambach A, Manns MP, Bock M. Induction of a mature hepatocyte phenotype in adult liver derived progenitor cells by ectopic expression of transcription factors. Stem Cell Res 2011; 6(3):251-61.

18. Armour SM, Remsberg JR, Damle M, Sidoli S, Ho WY, Li Z, Garcia BA, Lazar MA. An HDAC3-PROX1 corepressor module acts on HNF $4 \alpha$ to control hepatic triglycerides. Nat Commun 2017;8(1):549.

19. Matsuo S, Ogawa M, Muckenthaler MU, Mizui Y, Sasaki S, Fujimura T, Takizawa M, Ariga N, Ozaki H, Sakaguchi M, Gonzalez FJ, Inoue Y. Hepatocyte nuclear factor 4alpha controls iron metabolism and regulates transferrin receptor 2 in mouse liver. J Biol Chem 2015; 290(52):30855-65.

20. Ning M, Koh KH, Pan X, Jeong H. Hepatocyte nuclear factor (HNF) 4alpha transactivation of cytochrome P450 (Cyp) 2d40 promoter is enhanced during pregnancy in mice. Biochem Pharmacol 2015;94(1):4652.

21. Choi SY, Koh KH, Jeong H. Isoform-specific regulation of cytochromes P450 expression by estradiol and progesterone. Drug Metab Dispos 2013;41(2):263-9.

22. Su Y, Chen Z, Yan L, Lian F, You J, Wang X, Tang N. Optimizing combination of liver-enriched transcription factors and nuclear receptors simultaneously favors ammonia and drug metabolism in liver cells. Exp Cell Res 2018;362(2):504-14.

23. Nishikawa T, Bell A, Brooks JM, Setoyama K, Melis M, Han B, Fukumitsu K, Handa K, Tian J, Kaestner KH, Vodovotz Y, Locker J, Soto-Gutierrez A, Fox IJ. Resetting the transcription factor network reverses terminal chronic hepatic failure. J Clin Invest 2015;125(4):153344.

24. Hatziapostolou M, Polytarchou C, Aggelidou E, Drakaki A, Poultsides GA, Jaeger SA, Ogata H, Karin M, Struhl K, Hadzopoulou-Cladaras M, Iliopoulos D. An HNF4alpha-miRNA inflammatory feedback circuit regulates hepatocellular oncogenesis. Cell 2011;147(6):1233-47. 25. Ning BF, Ding J, Liu J, Yin C, Xu WP, Cong WM, Zhang Q, Chen F, Han T, Deng X, Wang PQ, Jiang CF, Zhang JP, Zhang X, Wang HY, Xie WF. Hepatocyte nuclear factor 4alpha-nuclear factor-kappaB feedback circuit modulates liver cancer progression. Hepatology
2014;60(5):1607-19

26. Zhou Z, Xu MJ, Gao B. Hepatocytes: a key cell type for innate immunity. Cell Mol Immunol 2016;13(3):301-15.

27. Wang Z, Salih E, Burke PA. Hepatocyte nuclear factor-4 phosphorylation mediated by inflammatory response. FASEB J 2013;27(1_supplement):1038.1.

28. Wang Z, Bishop EP, Burke PA. Expression profile analysis of the inflammatory response regulated by hepatocyte nuclear factor $4 \alpha$. BMC genomics 2011;12:128.

29. Lazarevich NL, Shavochkina DA, Fleishman DI, Kustova IF, Morozova OV, Chuchuev ES, Patyutko YI. Deregulation of hepatocyte nuclear factor 4 (HNF4) as a marker of epithelial tumors progression. Exp Oncol 2010;32(3):167-71.

30. Enane FO, Shuen WH, Gu X, Quteba E, Przychodzen B, Makishima H, Bodo J, Ng J, Chee CL, Ba R, Seng Koh L, Lim J, Cheong R, Teo M, Hu Z, Ng KP, Maciejewski J, Radivoyevitch T, Chung A, Ooi LL, Tan YM, Cheow P-C, Chow P, Chan CY, Lim KH, Yerian L, Hsi E, Toh HC, Saunthararajah Y. GATA4 loss of function in liver cancer impedes precursor to hepatocyte transition. J Clin Invest 2017;127(9):3527-42.

31. Walesky C, Edwards G, Borude P, Gunewardena S, O’Neil M, Yoo B, Apte U. Hepatocyte nuclear factor 4 alpha deletion promotes diethylnitrosamine-induced hepatocellular carcinoma in rodents. Hepatology 2013;57(6):2480-90

32. Ning BF, Ding J, Yin C, Zhong W, Wu K, Zeng X, Yang W, Chen YX, Zhang JP, Zhang X, Wang HY, Xie WF. Hepatocyte nuclear factor 4 alpha suppresses the development of hepatocellular carcinoma. Cancer Res 2010;70(19):7640-51.

33. Xu Y, Zalzala M, Xu J, Li Y, Yin L, Zhang Y. A metabolic stress-inducible miR-34a-HNF4alpha pathway regulates lipid and lipoprotein metabolism. Nat Commun 2015;6:7466.

34. Ancey P-B, Ecsedi S, Lambert M-P, Talukdar FR, Cros M-P, Glaise D, Narvaez DM, Chauvet V, Herceg Z, Corlu A, Hernandez-Vargas H. TET-catalyzed 5-hydroxymethylation precedes HNF4A promoter choice during differentiation of bipotent liver progenitors. Stem Cell Rep 2017;9(1):264-78.

35. Vető B, Bojcsuk D, Bacquet C, Kiss J, Sipeki S, Martin L, Buday L, Bálint BL, Arányi T. The transcriptional activity of hepatocyte nuclear factor 4 alpha is inhibited via phosphorylation by ERK1/2. PLoS one 2017;12(2):e0172020

36. Jing R, Duncan CB. A small-molecule screen reveals that HSP90 $\beta$ promotes the conversion of induced pluripotent stem cell-derived endoderm to a hepatic fate and regulates HNF4A turnover. Development 2017;144(10):1764-74.

37. McDowell IC, Barrera A, D’Ippolito AM, Vockley CM, Hong LK, Leichter SM, Bartelt LC, Majoros WH, Song L, Safi A, Koçak DD, Gersbach CA, Hartemink AJ, Crawford GE, Engelhardt BE, Reddy TE. Glucocorticoid receptor recruits to enhancers and drives activation by motif-directed binding. Genome Res 2018;28(9):1272-84.

38. Rhee J, Inoue Y, Yoon JC, Puigserver P, Fan M, Gonzalez FJ, Spiegelman BM. Regulation of hepatic fasting response by PPAR $\gamma$ coactivator-1 $\alpha$ (PGC-1): Requirement for hepatocyte nuclear factor $4 \alpha$ in gluconeogenesis. Proc Natl Acad Sci USA 2003;100(7):4012-7.

39. Han S, Li T, Ellis E, Strom S, Chiang JYL. A novel bile acid-activated vitamin $\mathrm{D}$ receptor signaling in human hepatocytes. Mol Endo- 
crinol 2010;24(6):1151-64.

40. Kodama S, Yamazaki Y, Negishi M. Pregnane X receptor represses HNF $4 \alpha$ gene to induce insulin-like growth factor-binding protein IGFBP1 that alters morphology of and migrates HepG2 cells. Mol Pharmacol 2015;88(4):746-57.

41. Meng F, Su X, Li W, Zheng Y. Ginsenoside Rb3 strengthens the hypoglycemic effect through AMPK for inhibition of hepatic gluconeogenesis. Exp Ther Med 2017;13(5):2551-7.
42. Liu QL YM, Zhang MZ, Guan M. 18ß-glycyrrhetinic acid reduces VLDL secretion as a modulator for HNF4a. Endocrine Abstracts 2017;49: EP801.

43. Zolfaghari R, Ross AC. Hepatocyte nuclear factor $4 \alpha$ (HNF $4 \alpha$ ) in coordination with retinoic acid receptors increases all-trans-retinoic acid-dependent CYP26A1 gene expression in HepG2 human hepatocytes. J Cell Biochem 2014;115(10):1740-51. 